\title{
Morbidity of acute pancreatitis: the effect of aprotinin and glucagon*
}

\author{
MEDICAL RESEARCH COUNCIL MULTICENTRE TRIAL
}

SUMMARY In a double-blind, randomised trial, neither aprotinin nor glucagon given in relatively high doses for five days influenced the rate of recovery or incidence of complications in 257 patients with acute pancreatitis.

We have previously reported the failure of both glucagon and aprotinin (Trasylol) to influence the death rate from acute pancreatitis. ${ }^{1}$ Data from the same multicentre trial have now been analysed to show whether either agent influenced the course of the illness in any other way.

\section{Methods}

\section{PATIENTS}

The details of this randomised, double-blind trial have already been described fully in our paper on mortality. ${ }^{1}$ In brief, patients entered the trial if they had an appropriate clinical history no longer than 72 hours and had either a serum amylase greater than $2000 \mathrm{IU} / 1$ (by the Phadebas method) or the finding of acute pancreatitis at emergency laparotomy. Each patient was allotted randomly to one of three treatment groups, each of which appeared to receive both aprotinin and glucagon, but actually received one of the following combinations: active glucagon with aprotinin placebo, active aprotinin with glucagon placebo, placebo for both aprotinin and glucagon. Patients were allocated to these groups in the ratios of $1: 1: 2$.

The doses of the drugs were:

Aprotinin: 500000 units by IV bolus injection followed by

300000 units by six hourly continuous infusion for five days - that is,

1200000 units in every 24 hours.

\footnotetext{
*This paper is written by Mr Alan G Cox, Professor P Armitage, and Mr R Hogg with assistance from the other members of the MRC Working Party on the treatment of acute pancreatitis: Professor R B Welbourn (Chairman), Mr O J A Gilmore, Mr C MacKay, Mr J E Trapnell, and Mr R C N Williamson, with representatives of Bayer Pharmaceuticals Ltd and Eli Lilly and Co Ltd present by invitation.

Glucagon: $2 \mathrm{mg}$ by IV bolus injection followed by $2 \mathrm{mg}$ by six hourly continuous infusion for five days-that is, $8 \mathrm{mg}$ in every 24 hours.

Apart from these drugs, every participating centre agreed to a restricted treatment regime consisting of nasogastric aspiration, intravenous fluids, and analgesics as required. No other treatment was used routinely, although for obvious ethical reasons the centres were able to give any additional treatment they felt necessary in individual patients. These additional treatments were entered in a standard data document, which was also used to record the presenting features, the findings on daily clinical examination, and the results of blood tests for the first seven days (as performed by standard methods in each hospital). Subsequent events, including complications and results of biliary radiology, were also recorded. The data sheets contained very few gaps in the information required. As reported previously, ${ }^{1}$ the three treatment groups were similar in terms of age, sex, presenting clinical and laboratory features, and aetiological factors. The numbers of patients in the treatment groups are shown in Table 1.

Table 1 Numbers of patients

\begin{tabular}{llccc}
\hline & \multicolumn{2}{l}{ Treatment group } & \\
\cline { 2 - 4 } & Placebo & Aprotinin & Glucagon & Total \\
\hline Survived & 110 & 60 & 60 & 230 \\
Died & 13 & 6 & 8 & 27 \\
Total & 123 & 66 & 68 & 257 \\
\hline
\end{tabular}

INDICATORS OF RECOVERY

Three variables were studied to assess the rate of recovery. (1) The duration of pain was defined as the time from the start of the trial drugs to the cessation of the presenting abdominal pain; the number of days on which parenteral analgesics were required was also recorded. (2) The duration of ileus was 
taken as the time from the start of treatment until the first passage of flatus. (3) The centres also recorded the length of hospital stay excluding days when the patient could not be discharged for purely non-medical reasons-for example, adverse social circumstances.

\section{COMPLICATIONS}

Participants were asked to make a daily clinical assessment and to note particularly the occurrence of 12 types of complication which were defined in the following way according to standard clinical practice: (1) chest complications-bronchopulmonary infections, lung collapse, and pleural effusions recognised on clinical or radiological examination; (2) jaundice-observed clinically and confirmed biochemically; (3) gastrointestinal bleeding-haematemesis or melaena requiring blood transfusion; (4) venous thromboembolism-diagnosed clinically; (5) pancreatic 'mass'-a palpable epigastric mass without the features of an abscess; (6) pancreatic abscess-a palpable epigastric mass thought to be septic; (7) hypocalcaemia-total serum calcium below $1.75 \mathrm{mmol} / \mathrm{l}$; (8) prolonged ileus-bowel sounds absent and no flatus for more than seven days; (9) septicaemia-a positive blood culture; (10) renal failure-a raised blood urea requiring special measures such as diuretics or dialysis; (11) toxic psychosis-a psychotic state occurring as an integral part of the acute illness; (12) GreyTurner sign-bruising in the flank.

The adoption of clinically based definitions for most of these complications was deliberate policy by the Working Party as the multicentre basis of the trial involved hospitals with varying investigative facilities. For the same reason, the methods of investigations used were those readily available at the outset of the trial in 1974 when, for example, ultrasound was not so widely used as now.

The incidences of these complications were compared in the three treatment groups as a whole as well as in various subgroups. As it would be unrealistic to present the full results of all these comparisons, we also calculated the average number of complications per patient in each group.

\section{STATISTICAL ANALYSIS}

Tabulations were produced by application of a standard computer package. ${ }^{2}$ Standard significance tests (analysis of variance and test for comparison of means, $x^{2}$ tests for comparison of proportions) were carried out after scrutiny of the tables to identify aspects of possible interest.

\section{Results}

The findings were analysed to see if any of the three treatment groups fared better than any other in terms of recovery and incidence of complications. The analysis was performed for all survivors, for dead patients, and for the following subgroups of the survivors: men and women; different age groups (up to 40 years, 50-69 years, 70 years and over); whether or not there had been an attack of pan-

Table 2 Pain in treatment groups

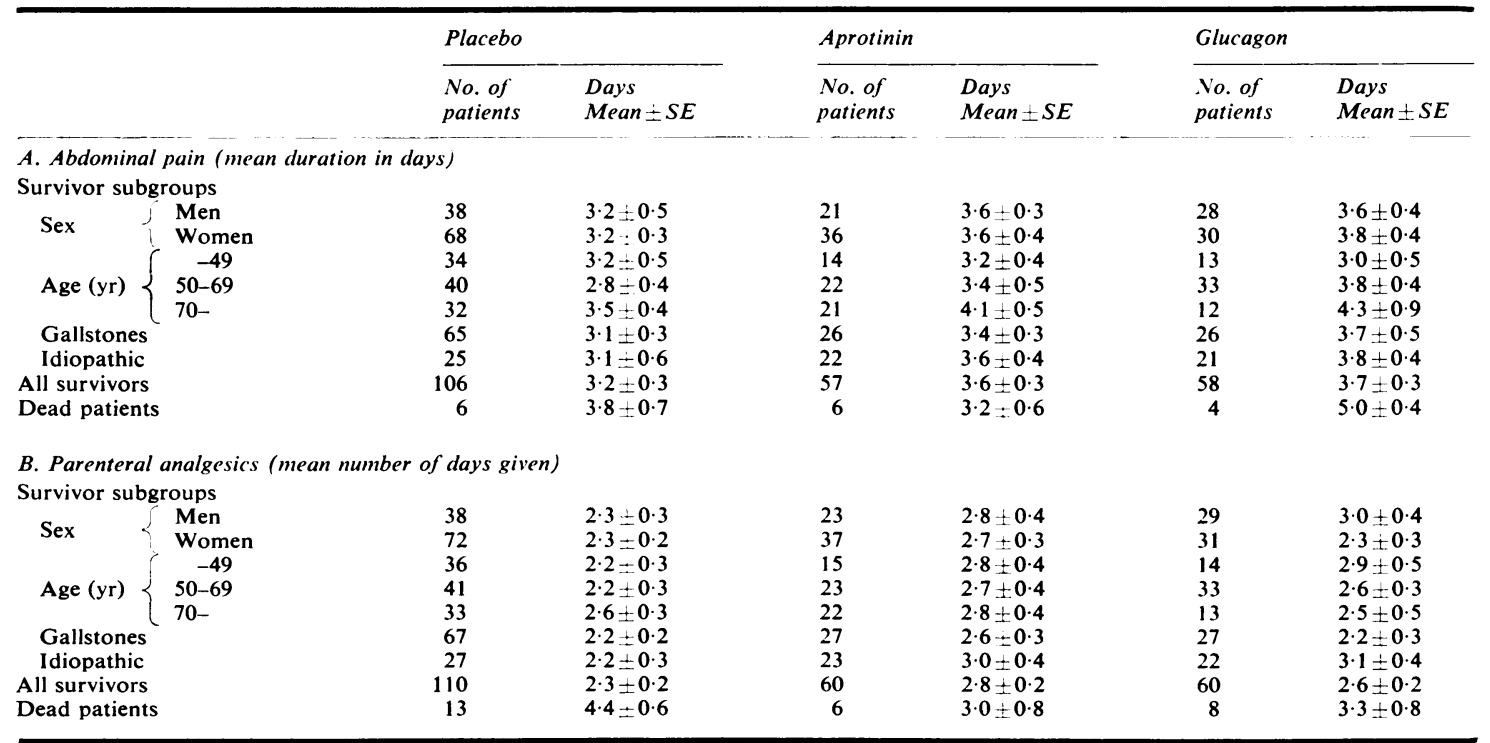


creatitis in the past; and aetiological category (gallstones, alcohol, idiopathic, previous biliary surgery, and miscellaneous). This analysis produced a vast quantity of information which would daunt even the most diligent reader, and so the data have been condensed substantially to present a fair comparison of the treatment groups. Every attempt has been made to include anything of importance or interest and it was considered unnecessary to include information on all the subgroups mentioned above.
A fuller set of tables is available on request. $\dagger$

RATE OF RECOVERY

In almost all the subgroups of patients, abdominal pain continued for an average of about three days and parenteral analgesics were given for between one and two days (Table 2); the duration of abdominal pain was not recorded completely in a number of patients, particularly among those who †From Mr Alan G Cox, MD, FRCS, Northwick Park Hospital, Harrow, Middlesex.

Table 3 Duration of ileus

\begin{tabular}{|c|c|c|c|c|c|c|}
\hline & \multicolumn{6}{|c|}{ Mean number of days } \\
\hline & \multicolumn{2}{|l|}{ Placebo } & \multicolumn{2}{|c|}{ Aprotinin } & \multicolumn{2}{|c|}{ Glucagon } \\
\hline \multicolumn{7}{|l|}{ Survivor subgroups } \\
\hline $\begin{array}{l}\text { Sex }\left\{\begin{array}{l}\text { Men } \\
\text { Women } \\
-49 \\
50-69 \\
70-\end{array}\right. \\
\text { Age (yr) } \\
\text { Gallstones } \\
\text { Idiopathic } \\
\text { All survivors } \\
\text { Dead patients }\end{array}$ & $\begin{array}{r}34 \\
56 \\
30 \\
35 \\
25 \\
55 \\
22 \\
90 \\
7\end{array}$ & $\begin{array}{l}1.9 \pm 0.2 \\
1.8 \pm 0.2 \\
1.6 \pm 0.2 \\
1.8 \pm 0.2 \\
2 \cdot 2 \pm 0.3 \\
2.0 \pm 0.2 \\
1 \cdot 7 \pm 0.2 \\
1.8 \pm 0.1 \\
3 \cdot 7 \pm 0.7\end{array}$ & $\begin{array}{r}16 \\
31 \\
10 \\
19 \\
18 \\
21 \\
18 \\
47 \\
5\end{array}$ & $\begin{array}{l}2 \cdot 3 \pm 0.5 \\
2 \cdot 2 \pm 0 \cdot 2 \\
1 \cdot 8 \pm 0 \cdot 3 \\
2 \cdot 1 \pm 0 \cdot 3 \\
2 \cdot 6 \pm 0 \cdot 4 \\
2 \cdot 4 \pm 0 \cdot 4 \\
2 \cdot 1 \pm 0.3 \\
2 \cdot 2 \pm 0 \cdot 2 \\
4 \cdot 4 \pm 1 \cdot 5\end{array}$ & $\begin{array}{r}26 \\
26 \\
9 \\
30 \\
13 \\
22 \\
20 \\
52 \\
4\end{array}$ & $\begin{array}{l}2 \cdot 2 \pm 0 \cdot 3 \\
2 \cdot 1 \pm 0 \cdot 3 \\
2 \cdot 1 \pm 0 \cdot 5 \\
2 \cdot 0 \pm 0 \cdot 2 \\
2 \cdot 6 \pm 0 \cdot 5 \\
2 \cdot 4 \pm 0 \cdot 3 \\
2 \cdot 2 \pm 0 \cdot 3 \\
2 \cdot 2 \pm 0 \cdot 2 \\
2 \cdot 8 \pm 0 \cdot 3\end{array}$ \\
\hline
\end{tabular}

Table 4 Duration of hospital stay

\begin{tabular}{|c|c|c|c|c|c|c|}
\hline & \multicolumn{6}{|c|}{ Mean number of days } \\
\hline & \multicolumn{2}{|l|}{ Placebo } & \multicolumn{2}{|c|}{ Aprotinin } & \multicolumn{2}{|c|}{ Glucagon } \\
\hline \multicolumn{7}{|l|}{ Survivor subgroups } \\
\hline $\begin{array}{l}\text { Sex }\left\{\begin{array}{l}\text { Men } \\
\text { Women } \\
-49 \\
50-69 \\
70-\end{array}\right. \\
\text { Age (yr) } \\
\text { Gallstones } \\
\text { Idiopathic } \\
\text { All survivors } \\
\text { Dead patients }\end{array}$ & $\begin{array}{r}38 \\
71 \\
35 \\
41 \\
33 \\
66 \\
27 \\
109 \\
13\end{array}$ & $\begin{array}{l}15 \cdot 3 \pm 2 \cdot 5 \\
13 \cdot 3 \pm 0 \cdot 9 \\
11 \cdot 6 \pm 1 \cdot 1 \\
14 \cdot 0 \pm 2 \cdot 1 \\
16 \cdot 4 \pm 1 \cdot 8 \\
14 \cdot 4 \pm 1 \cdot 5 \\
12 \cdot 0 \pm 1 \cdot 4 \\
14 \cdot 0 \pm 1 \cdot 1 \\
16 \cdot 5 \pm 3 \cdot 8\end{array}$ & $\begin{array}{r}23 \\
37 \\
15 \\
23 \\
22 \\
27 \\
23 \\
60 \\
6\end{array}$ & $\begin{array}{l}11 \cdot 9 \pm 1 \cdot 0 \\
14 \cdot 5 \pm 1 \cdot 9 \\
12 \cdot 1 \pm 1 \cdot 3 \\
15 \cdot 5 \pm 2 \cdot 9 \\
12 \cdot 3 \pm 1 \cdot 0 \\
12 \cdot 4 \pm 2 \cdot 1 \\
12 \cdot 3 \pm 0 \cdot 9 \\
13 \cdot 5 \pm 1 \cdot 2 \\
25 \cdot 7 \pm 10 \cdot 1\end{array}$ & $\begin{array}{r}29 \\
31 \\
14 \\
33 \\
13 \\
27 \\
22 \\
60 \\
8\end{array}$ & $\begin{array}{l}16 \cdot 1 \pm 2 \cdot 9 \\
15 \cdot 9 \pm 2 \cdot 0 \\
16 \cdot 7 \pm 5 \cdot 3 \\
15 \cdot 1 \pm 1 \cdot 7 \\
17 \cdot 5 \pm 3 \cdot 9 \\
16 \cdot 5 \pm 2 \cdot 5 \\
16 \cdot 0 \pm 3 \cdot 4 \\
16 \cdot 0 \pm 1 \cdot 7 \\
28 \cdot 5 \pm 14 \cdot 2\end{array}$ \\
\hline
\end{tabular}

Table 5 Incidence of complications

\begin{tabular}{|c|c|c|c|c|c|c|}
\hline & \multicolumn{3}{|l|}{ Survivors } & \multicolumn{3}{|c|}{ Dead patients } \\
\hline & Placebo & Aprotinin & Glucagon & Placebo & Aprotinin & Glucagon \\
\hline Total no. of patients in group & 110 & 60 & 60 & 13 & 6 & 8 \\
\hline Chest & 19 (17) & 7 (12) & $11(18)$ & $10(77)$ & $3(50)$ & $5(63)$ \\
\hline DVT/PE & 0 & $\mathbf{0}$ & 1 (2) & $1(8)$ & 0 & o \\
\hline G-I bleed & 4 (4) & $\mathbf{0}$ & 1 (2) & $3(23)$ & $1(17)$ & $2(25)$ \\
\hline Jaundice & $17(16)$ & $15(25)$ & $11(18)$ & $6(46)$ & $2(33)$ & $3(38)$ \\
\hline Pseudocyst & 4 (4) & 4 (7) & $6(10)$ & 5 (39) & 2 (33) & $4(50)$ \\
\hline Abscess & $\mathbf{0}$ & $\mathbf{0}$ & $\mathbf{0}$ & $2(15)$ & $1(17)$ & 0 \\
\hline Hypocalcaemia & 7 (6) & 1 (2) & 4 (7) & $5(39)$ & $4(67)$ & $2(25)$ \\
\hline Ileus & 1 (1) & 2 (3) & o & $2(15)$ & 0 & 0 \\
\hline Septicaemia & 2 (2) & 1 (2) & 2 (3) & $4(31)$ & 0 & $3(38)$ \\
\hline Renal failure & 2 (2) & 0 & 1 (2) & $3(23)$ & $2(33)$ & $3(38)$ \\
\hline Toxic psychosis & 3 (3) & 4 (7) & 1 (2) & $2(15)$ & $2(33)$ & $2(25)$ \\
\hline Grey-Turner sign & 1 (1) & o & 1 (2) & 0 & 0 & 0 \\
\hline
\end{tabular}

*Number of patients with each complication with percentage incidence in parentheses. 
died. It is clear that neither active agent had a favourable effect on pain and, indeed, the average values for the placebo group are almost universally the best. The average duration of ileus was around two days (Table 3) and there was virtually no difference between the three treatment groups. Similarly, there is no suggestion that either active agent influenced the duration of hospital stay, the mean values in the survivor subgroups varying between 11 and 17 days (Table 4).

COMPLICATIONS

The incidence of each complication in the three treat-
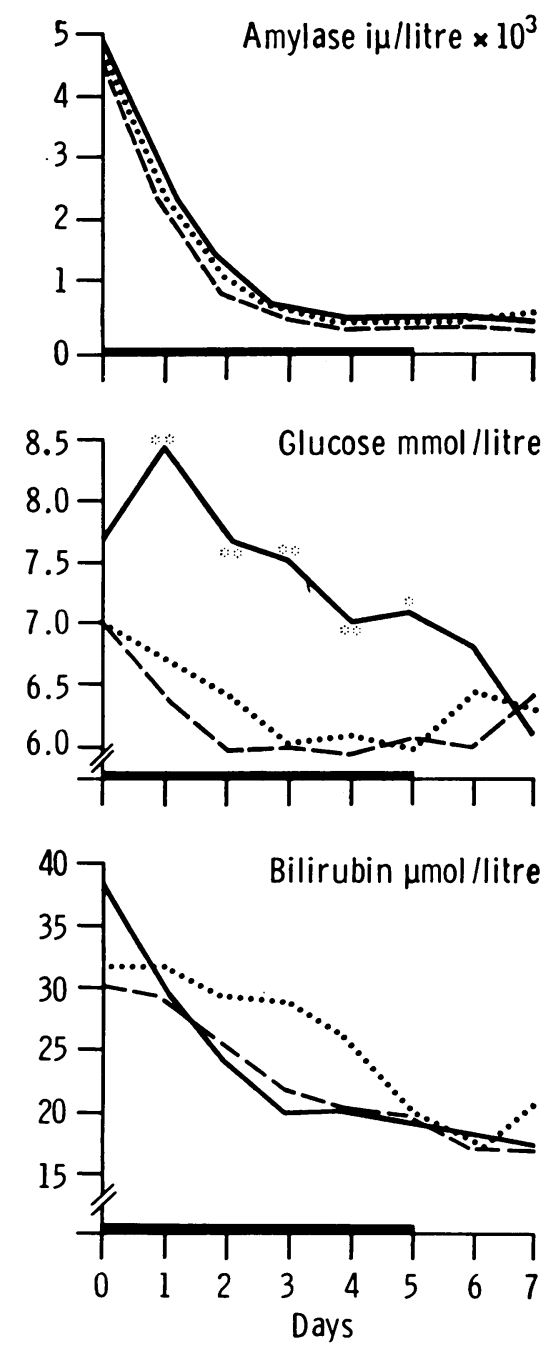

ment groups is shown in Table 5. There is no statistical evidence of a trend in favour of either of the active treatments. The mean number of complications per patient (Table 6) reveals a relatively small scatter around 0.5 in almost all the subgroups. Indeed, the only significant difference found in the whole analysis was for the alcohol subgroups, where, on very small numbers ( 23 patients in all), the differences reached a marginal level of significance $(P=0.03)$ in favour of glucagon.

BIOCHEMICAL DATA (Figure)

There are very few differences between the treatment
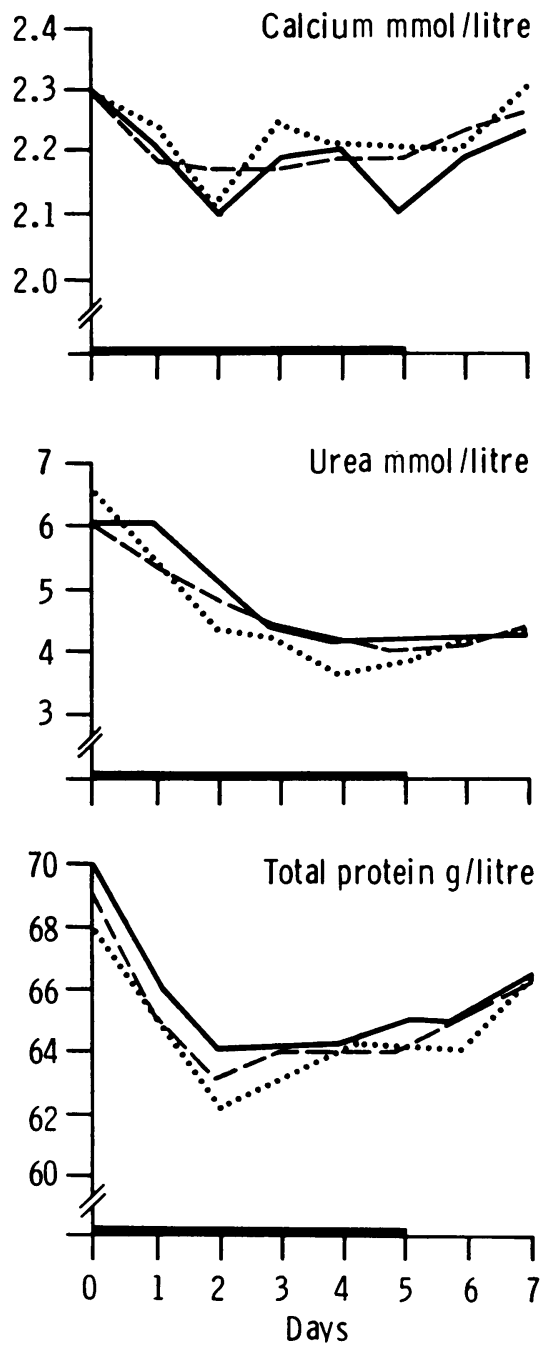

Figure Average daily values of the six biochemical variables measured immediately before treatment $($ day 0$)$ and daily thereafter for seven days. The trial drugs were given over the first five days. (Key: placebo - - - Glucagon _- Aprotinin ....... Asterisks indicate values significantly higher than in the other two groups $-{ }^{* *} \mathrm{P}<0.001$ and ${ }^{*} \mathrm{P}<0.01$.) 
Table 6 Number of complications per patient

\begin{tabular}{|c|c|c|c|c|c|c|c|}
\hline & & \multicolumn{2}{|l|}{ Placebo } & \multicolumn{2}{|c|}{ Aprotinin } & \multicolumn{2}{|c|}{ Glucagon } \\
\hline & & $\begin{array}{l}\text { No. of } \\
\text { patients }\end{array}$ & $\begin{array}{l}\text { No./patient } \\
\text { Mean } \pm S E\end{array}$ & $\begin{array}{l}\text { No. of } \\
\text { patients }\end{array}$ & $\begin{array}{l}\text { No./patient } \\
\text { Mean } \pm S E\end{array}$ & $\begin{array}{l}\text { No. of } \\
\text { patients }\end{array}$ & $\begin{array}{l}\text { No./patient } \\
\text { Mean } \pm S E\end{array}$ \\
\hline \multicolumn{8}{|c|}{ Survivor subgroups } \\
\hline \multirow{3}{*}{$\operatorname{Sex}\{$} & Men & 38 & $0.7 \pm 0.2$ & 23 & $0.7 \pm 0.2$ & 29 & $0.8 \pm 0.2$ \\
\hline & Women & 72 & $0 \cdot 5 \div 0 \cdot 1$ & 37 & $0.5 \pm 0.1$ & 31 & $0.5 \pm 0.1$ \\
\hline & -49 & 36 & $0 \cdot 3 \pm 0 \cdot 1$ & 15 & $0 \cdot 5 \pm 0.2$ & 14 & $0.6 \pm 0.2$ \\
\hline \multirow{2}{*}{ Age (yr) } & $50-69$ & 41 & $0.6 \pm 0.2$ & 23 & $0.5 \pm 0.2$ & 33 & $0.6 \pm 0.2$ \\
\hline & $70-$ & 33 & $0 \cdot 7 \pm 0 \cdot 2$ & 22 & $0.7 \pm 0.2$ & 13 & $0.9 \pm 0.2$ \\
\hline \multicolumn{2}{|c|}{ Gallstones } & 67 & $0 \cdot 5 \pm 0 \cdot 1$ & 27 & $0 \cdot 7 \pm 0 \cdot 2$ & 27 & $0.9 \pm 0.2$ \\
\hline \multicolumn{2}{|l|}{ Idiopathic } & 27 & $0.7 \pm 0.3$ & 23 & $0 \cdot 3 \pm 0 \cdot 1$ & 22 & $0.5 \pm 0.1$ \\
\hline \multicolumn{2}{|l|}{ Alcohol } & 8 & $0.6=0.2$ & 7 & $1 \cdot 0 \pm 0 \cdot 3$ & 8 & $0 \cdot 1 \pm 0 \cdot 1$ \\
\hline \multicolumn{2}{|l|}{ All survivors } & 110 & $0.6 \div 0.1$ & 60 & $0.6 \pm 0.1$ & 60 & $0.7 \pm 0.1$ \\
\hline \multicolumn{2}{|l|}{ Dead patients } & 13 & $3 \cdot 3 \pm 0 \cdot 5$ & 6 & $2 \cdot 8 \div 0 \cdot 3$ & 8 & $3.0 \pm 0.9$ \\
\hline
\end{tabular}

group in the mean daily values for the six biochemical variables measured during the first week of the illness. The relatively high blood glucose levels in the glucoagon group can be attributed partly to the rather high initial value in these patients and partly to the effect of glucagon itself. The bilirubin values on the second to fourth days in the aprotinintreated patients are not significantly different from those in the other two groups.

\section{Discussion}

The over-riding conclusion is quite clear: neither glucagon nor aprotinin affected the course of acute pancreatitis in surviving patients. This is consistent with our previously reported finding, ${ }^{1}$ that the risk of dying from this disease is not influenced by either agent. Aprotinin was also found to be ineffective in preventing death and major complications in the Glasgow trial of this agent. ${ }^{3}$

There is no simple and universally agreed way to compare recovery from an illness in different groups of patients. In the absence of any single, measurable criterion, it is necessary to examine many variables which can be analysed separately or combined and graded in some arbitrary way. We have employed both approaches with computer assistance in order to make maximal use of the data from the trial. The result is a vast number of comparisons of the three treatment groups, from which it has been necessary to select representative aspects.

Our calculation of the average number of complications per patient gives equal weight to each type of complication whatever its nature and severity. However, the similarity of the mean values supports the view that there is little if any difference between the treatment groups. This is compatible with the examination of individual complications in Table 5 in which there is no discernible trend in favour of any particular treatment. In assessing the rate of recovery, the treatment groups behaved in almost exactly the same way. It is particularly disappointing that we could find no support for the assertion that glucagon provides rapid relief of pain in acute pancreatitis. ${ }^{4-6}$

Although the number of results presented in this paper is limited, computer analyses have been carried out using many other different permutations. The outcome is one of uniformity between the three treatment groups. The only result (for the alcohol subgroup) which in isolation suggests that one treatment might be better than another is statistically unremarkable when hundreds of analyses have been performed.

In the absence of the slightest hint of a trend in any particular direction, we conclude that the relatively high dose regime of both aprotinin and glucagon have no effect on acute pancreatitis.

The Working Party wishes to thank Mr P Wilding of the Wolfson Research Laboratories, Queen Elizabeth Medical Centre, Birmingham, for advice on the amylase estimation, Bayer Pharmaceuticals Ltd. and Eli Lilly and Co. Ltd. for the supplies of aprotinin, glucagon, and placebo, and the surgeons and patients of the following centres, and above all the local supervising surgeons; Bangour General Hospital (Mr A A Gunn), Belfast City Hospital (Mr R C Curry), Bristol Hospitals (Mr R C N Williamson, Mr R G Hughes, Mr N I Ramus, Mr M H Ornstein, Mr B A Storey), Glasgow Western Infirmary (Mr W R Murray), North Middlesex Hospital (Mr B Brara), Manchester Royal Infirmary (Mr D Allan, Mr R J Williams), Newcastle upon Tyne Hospitals (Mr D C Britton), Norfolk and Norwich Hospitals (Mr M H Jourdan, Mr R Lightwood, Mr R Motsom), Scarborough Hospital (Mr A Pollock, Miss M Evans), Royal Berkshire and Battle Hospitals, Reading (Mr S B Janvrin, Mr B Mayou). The failure to mention the contribution from Reading in our previous paper ${ }^{1}$ is deeply regretted. 


\section{References}

${ }^{1}$ MRC Working Party on the Treatment of Acute Pancreatitis. Death from acute pancreatitis. Lancet 1977; 2: 632-5.

${ }^{2} \mathrm{Nie} \mathrm{NH}$, Hull $\mathrm{CH}$, Jenkins JG, Steinbrenner K, Bent DH. Statistical package for the social sciences. 2nd ed New York: McGraw-Hill, 1975.

${ }^{3}$ Imrie CW, Banjamin IS, Ferguson JC, McKay AJ, Mackenzie I, O'Neill J, Blumgart LH. A single-centre, double-blind trial of Trasylol therapy in primary acute pancreatitis. Br J Surg 1978; 65: 337-41.

${ }^{4}$ Condon JR, Knight M, Day JL. Glucagon therapy in acute pancreatitis. Br J Surg 1973; 60: 509-11.

${ }^{5}$ Waterworth TA, Bevan PG. Effect of glucagon on pain in acute pancreatitis (Abstract). Ann R Coll Surg Engl 1976; 58: 323.

${ }^{6}$ Gilsanz V, Oteyza CP, Rebollar JL. Glucagon vs Anticholinergies in the treatment of acute pancreatitisa double-blind controlled trial. Arch Intern Med 1978; 138: $535-8$. 